\title{
PANDANGAN ORANG TUA TERKAIT PENDIDIKAN SEKS UNTUK ANAK USIA DINI
}

\author{
Risty Justicia \\ Universitas Pendidikan Indonesia, Kampus Purwakarta \\ Email : justiciaristy@gmail.com
}

\begin{abstract}
ABSTRAK
Artikel ini mengkaji penelitian terkait pandangan orang tua terhadap pendidikan seks untuk anak usia dini. Penelitian ini dilatarbelakangi oleh maraknya tindak kejahatan seksual bagi anak. Salah satu faktor yang diasumsikan sebagai penyebab adalah kurangnya informasi kepada anak terkait dengan tindakan pencegahan dan pertahanan diri yang dapat diberikan dalam pendidikan seks bagi anak. Pendidikan seks bagi anak sendiri masih dianggap tabu di kalangan masyarakat. Metode yang digunakan dalam penelitian ini adalah studi kasus dengan melibatkan empat orang responden yang terdiri dari dua orang ibu dan dua orang ayah. Hasil dalam penelitian ini menunjukkan bahwa orang tua memiliki pandangan tentang pentingnya pendidikan seks bagi anak, namun masih terbatas pada pengenalan jenis kelamin anak sebagai perempuan atau laki-laki. Adapun rekomendasi yang diberikan yaitu orang tua hendaknya mencari informasi yang akurat dan tepat tentang berbagai cara dan metode pengenalan pendidikan seks bagi anak yang sesuai dengan tahapan perkembangannya.
\end{abstract}

Kata Kunci: Pandangan Orang tua; Pendidikan Seks; Anak Usia Dini.

\begin{abstract}
This paper examines research related to parents' views on sex education for early childhood. This research is motivated by the rise of sexual crimes for children. One of the factors that are assumed to be the cause is the lack of information to the child related to the precautions and self-defense that can be provided in child sex education. Sex education for children is still considered taboo in the community. The method used in this study is a case study involving four respondents consisting of two mothers and two fathers. The results in this study indicate that parents have views about the importance of sex education for children, but are still limited to the introduction of the sex of children as women or men. As for recommendations given that parents should seek accurate and precise information about various ways and methods of introducing sex education for children in accordance with the stages of its development.
\end{abstract}

Keywords: Parent Views; Sex Education; Early Childhood.

\section{PENDAHULUAN}

Tindak kejahatan seksual terhadap anak saat ini seringkali terjadi. Berdasarkan data Komisi Perlindungan Anak Indonesia (KPAI), tindak kejahatan seksual pada anak pada tahun 2016 tercatat sebanyak 78 kasus kejahatan seksual secara online terhadap anak, 120 kasus anak sebagai korban kejahatan seksual, dan 41 kasus anak sebagai korban eksploitasi seks komersial (KPAI, 2016). Data tersebut menandakan bahwa tidak kejahatan seksual pada anak masih cenderung tinggi.

Mariani \& Bactiar (2010), memaparkan bahwa salah satu penyebab permasalahan seks pada anak adalah fasilitas yang dimiliki anak yang memungkinkan mengkonsumsi 
informasi vulgar dari media elektronik yang memiliki jaringan internet yaitu, gadget, televisi dan handphone. Media yang paling sering digunakan untuk melihat konten pornografi adalah telepon genggam (handphone). Serupa dengan penelitian Rahmawati (2012) pada anak sekolah dasar negeri 16 Banda Aceh menyatakan anak yang mendapatkan informasi perilaku seksual dari media cetak maupun media elektronik menunjukan persentasi yang cukup tinggi untuk perilaku seksual. Hal ini menjadi darurat karena anak secara tidak langsung menjadi pengkonsumsi aktif.

Data yang dipublikasikan KPAI, sejak tahun 2011 hingga 2014, jumlah anak korban pornografi dan kejahatan online di Indonesia telah mencapai jumlah 1.022 anak. Secara rinci dipaparkan, anak-anak yang menjadi korban pornografi online sebesar $28 \%$, pornografi anak online $21 \%$, prostitusi anak online $20 \%$, objek cd porno $15 \%$ serta anak korban kekerasan seksual online 11\% (Setyawan, 2015). Selain itu, Samsul (Kusmiati, 2015) menguatkan bahwa latar belakang kasus kekerasan seksual di antaranya karena pengaruh media pornografi sebanyak 81 kasus, terangsang dengan korban 178 kasus, hasrat tersalurkan sebanyak 298 kasus.

Maraknya kasus kekerasan seksual pada anak mengingatkan betapa pentingnya masalah mengenai pengetahuan seks pada anak, maka kesadaran akan pendidikan seks perlu ditumbuhkan pada masa anak usia dini (SIECUS, 2004; Maslihah, 2006). Kesadaran pendidikan seks anak bertujuan agar anak dapat menjaga diri dari pelaku kekerasan seksual anak. Permasalahan utama, pelaku kekerasan seksual merupakan merupakan keluarga dekat korban yaitu paman, sepupu dan pengasuh. Pernyataan ini dikuatkan oleh Nainggolan (2008) yang menyatakan para pelaku kekerasan seksual 68 persen dilakukan oleh orang yang dikenal anak, termasuk 34 persen dilakukan oleh orangtua kandung sendiri.

Maka dari itu dapat dikatakan bahwa pendidikan seks sangat penting pengaruhnya dalam proses kehidupan anak Pentingnya anak mempelajari mengenai pendidikan seks sama pentingnya dengan anak belajar perkembangan kognitif, perkembangan sosial dan kemandirian (Counterman \& Kirkwood, 2013; Kurnia \& Tjandra, 2012). Agar pendidikan seks pada anak tidak keliru, maka perlu adanya pendidikan seks yang tepat bagi anak usia dini sehingga anak dapat berperilaku dengan tepat.

Pendidikan seks merupakan pendidikan yang berkaitan dengan proses penyampaian informasi dan pembentukan sikap mengenai seks atau jenis kelamin, identitas jenis kelamin, relasi-antar jenis kelamin dan keintiman yang lebih kepada kedekatan (Kurnia \& Tjandra, 2012; Luluk, 2015). Berbeda dengan pendidikan seks remaja, pendidikan seks pada anak tidak mengajarkan mengenai perilaku seksual orang dewasa tapi membahas seputar perbedaan fungsi anatomi tubuh lakilaki dan perempuan.

Pendidikan seks anak usia dini bukan hanya membahas seputar perbedaan anatomi antara laki-laki dan 
perempuan atau perkembangan alat reproduksi. Pendidikan seks anak juga membahas bagaimana membekali anak dengan keterampilan untuk memilih tindakan yang akan diambil, mengembangkan kepercayaan diri, meningkatkan kompetensi anak untuk menentukan sikap saat menghadapi sebuah situasi (SEF, 2011). Melalui pengembangan percaya diri dan kemampuan menentukan sikap inilah diharapkan anak akan dapat melindungi dirinya terhadap kejahatan atau pelecehan seksual, penyimpangan perilaku seksual, penyakit menular seperti HIV dan AIDS.

Berdasarkan hal tersebut, tersirat bahwa tujuan utama dalam pendidikan seks pada anak usia dini hakikatnya adalah mengenalkan anak tentang jenis kelamin dan cara menjaganya baik dari sisi kesehatan, kebersihan, kemamanan serta keselamatan berdasarkan tingkat perkembangan anak (Counterman \& Kirkwood, 2013). Pendidikan seks ini sebaiknya dimulai diajarkan ketika masa usia pra sekolah dimana pada usia ini anak sudah mengenal alat kelaminya.

Orang tua merupakan lingkungan pertama dan utama dalam kehidupan anak, oleh karena itu pendidikan seks baiknya dilakukan di dalam lingkungan rumah dilakukan bersama orang tua (SIECUS, 2011; Sciaraffa \& Randolph, 2011; Honig, 2000). Pendidikan seks sebaiknya dilakukan di dalam rumah sebab pembicaraan mengenai seks harus dilakukan secara terbuka dan situasi yang nyaman. Pembicaraan pendidikan seks pada anak usia dini yang dilakukan dirumah akan mempermudah mempelajari pendidikan seks dengan situasi-situasi sehari-hari (Cohen, 2009; Sugiasih, 2010). Misalnya saat anak bertanya mengapa organ tubuh laki-laki berbeda dengan perempuan atau mengapa anak laki-laki harus berdiri ketika buang air kecil berbeda dengan anak perempuan yang harus jongkok. Dari pertanyaan sederhana itu, orang tua bisa memulai menanamkan pendidikan seks mulai dari tingkat paling dasar mengenai organ tubuh hingga batasan sentuhan tubuh anak.

Di sinilah peran orang tua benarbenar penting dan menentukan, karena orang tua merupakan individu yang paling mengenal diri dan kebutuhan anaknya. Orang tua juga lebih mengetahui perubahan dan perkembangan anak setiap saat. Di samping juga orang tua yang paling dekat dan memahami karakter anaknya. Dengan demikian orang tua bisa memberi pendidikan seks secara alamiah sesuai tahapan-tahapan perkembangan anak yang menjadi tanggungannya.

Namun, kenyataanya pendidikan seks pada anak masih dianggap tabu oleh orang tua (Sciaraffa \& Randolph, 2011; Pitkoff, 2008; Counterman \& Kirkwood, 2013). Orang tua beranggapan pemberian pendidikan seks yang diberikan terlalu dini akan membuat anak penasaran dalam seks dan akan menjadikan anak sebagai pelaku aktif (Coleman \& Charles, 2009; Chrisman \& Chounchenour, 2002). Permasalahan ini bukan hanya terjadi di Indonesia saja, penelitian yang dilakukan Ching (2005) menunjukan 
bahwa orang tua di negara Amerika dan Hongkong memiliki kesulitan dalam memberikan pendidikan seksual pada anak. Penelitian tersebut menunjukan bahwa orangtua di Amerika dan Hongkong memiliki permasalahan yang sama dalam memberikan pendidikan seks pada anak. Orangtua kebingungan ketika memberikan antara pendidikan seksual dengan perilaku seksual orang dewasa (Counterman \& Kirkwood, 2013; Mil, 2015).

Berdasarkan latar belakang masalah di atas, penulis bermaksud untuk mengkaji lebih lanjut terkait pandangan orang tua tentang pendidikan seks untuk anak usia dini baik pandangan dari ayah maupun pandangan dari ibu.

\section{METODE PENELITIAN}

Metode penelitian yang digunakan adalah metode studi kasus (case study). sebagaimana diungkapkan Creswell (1998) Studi kasus disusun untuk memahami isu khusus, masalah, atau perhatian terhadap sesuatu dari kasus atau berbagai kasus yang ditentukan untuk memperoleh pemahaman terbaik (present an indepth understanding). Metode studi kasus yang berusaha menemukan makna, menyelidiki proses dan memperoleh pandangan dan pemahaman yang mendalam dari individu, kelompok, atau situasi.

Desain penelitian yang digunakan dalam penelitian ini adalah pendekatan kualitatif, karena dalam penelitian ini akan dilakukan kajian terhadap aktivitas manusia yang berlangsung dalam proses pendidikan secara alamiah. Adapun partisipan yang terlibat dalam penelitian ini adalah orang tua yang memilili anak yang usianya dibawah enam tahun sebanyak empat orang partisipan yang terdiri dari 2 orang bapak dan 2 orang ibu.

\section{HASIL DAN PEMBAHASAN}

Data dalam peneitian ini diperoleh dari hasil wawancara dan observasi yang dilakukan kepada empat orang subjek penelitian. Berdasarkan hasil wawancara dan observasi yang dilakukan penulis terkait pandangan dan pemahaman pada subjek pertama (Ibu A) tentang pendidikan seksual pada anak diperoleh hasil sebagai berikut:

“...Menurut saya perlu ya tapi mungkin kadarnya tergantung pada usia nya gitu yaa.. tergantung pada usia nya.. tetep kita harus memberikan pengetahuan umum soal seksualitas tapi tergantung sama usianya..."

(Wawancara Responden 1/Ibu A, 10

Mei 2016)

Responden pertama menekankan bahwa pendidikan seksual penting diberikan bagi sebuah pengetahuan bagi anak. Responden mengungkapkan bahwa pengetahuan seksualitas untuk anak usia dini perlu disesuaikan dengan usianya agar tidak terlalu berlebihan. Pandangan lain yang responden pertama miliki tentang pendidikan seksual dapat terlihat dari penggalan wawancara berikut:

...Memang menjadi seorang perempuan harus hati-hati. Makanya saya ingin anak perempuan saya ikut bela diri. Mau ikutan taekwondo atau 
karate juga gak masalah.. setidaknya anak saya bisa antisipasi kalo ada orang yang berniat jahat

(Wawancara

Responden $1 / \mathrm{Ibu}$

A, 10 Mei 2016)

Berdasarkan wawancara di atas responden menekankan bahwa anak perempuan harus lebih berhati-hati dalam menjaga dirinya sendiri. Adapun usaha preventif yang dilakukan oleh responden dalam menjaga anak perempuannya yaitu melalui kegiatan beladiri seperti taekwondo atau karate. Responden berharap anaknya dapat melakukan antisipasi apabila ada orang asing yang berniat buruk kepada dirinya. Hal tersebut didukung yang dipaparkan Nur Hasyim (Sucahyo, 2016), salah satu ketua organisasi pembela hak-hak perempuan di Yogyakarta yang menyatakan bahwa rata-rata setiap hari ada satu perempuan korban kekerasan yang mengadu. Dalam enam tahun terakhir, ada lebih dari 1.500 kasus dilaporkan, di mana 227 merupakan kasus perkosaan dan 128 kasus pelecehan sosial. Jumlah faktual di masyarakat diyakini jauh lebih tinggi, karena perempuan masih enggan melaporkan kasus perkosaan atau pelecehan seksual yang dialaminya.

Uraian di atas menekankan tentang tingginya tindak kekerasan seksual yang terjadi saat ini pada perempuan, namun beberapa fakta menunjukkan bahwa tindakan kekerasan seksual tersebut bukan hanya menimpa anak perempuan saja, anak laki-laki pun banyak yang menjadi korban kekerasan seksual. Berdasarkan catatan tahunan Komisi Perlindungan Anak Indonesia (Karahalis, 2014), pada 2012 jumlah korban anak yang mengalami kekerasan seksual ada 256 orang. Lalu pada 2013 jumlahnya meningkat menjadi 378 orang. Mayoritas korban kekerasan seksual adalah anak laki-laki dengan perbandingan persentase 60 persen anak laki laki dan 40 persen anak perempuan.

Sama halnya dengan pendapat responden pertama, responden kedua dari penelitian ini yaitu Ibu $R$ berpandangan bahwa pendidikan seksual penting untuk anak. Berikut kutipan wawancara yang menggambarkan kondisi tersebut:

“...Perlu sih.. Tapi harus digaris bawahi yang mana dulu. Umurumur sekarang mungkin pengenalan alat reproduksi dia aja dulu seperti apa, itu apa, bagaimana menjaganya untuk sekarang. Karena terlalu muda yaa nanti kan bertahap sesuai umur baru dikenalkan kan dia juga banyak bertanya nanti. Kalo sekarang kan Cuma pengen taunya ini apa itu apa..."

Wawancara Responden 2/Ibu R, 17 Mei

Dari hasil wawancara di atas Ibu $\mathrm{R}$ memiliki pandangan yang sama dengan responden pertama. Ibu $\mathrm{R}$ menekankan bahwa pendidikan seks untuk anak usia dini sebaiknya sesuai dengan tahapan usia anak. Ibu $\mathrm{R}$ mengangap bahwa anaknya masih terlalu muda untuk mendapatkan pendidikan seksual. Ibu $\mathrm{R}$ berpandangan bahwa materi pendidikan 
seksual yang sesuai untuk anak terdiri dari pengenalan alat reproduksi yang dimiliki anak dan juga usaha-usaha preventif anak terhindar dari predator kekerasan seksual. Sama halnya dengan pandangan Wardle (2007) bahwa konsep kematangan perkembangan anak usia dini salah satunya adalah perkembangan kesehatan seksual yang berkembang sejak usia dini. Namun orang tua hampir tidak memiliki pengetahuan mengenai perkembangan kesehatan seksual yang sehat untuk anak. Bukan hanya orang tua, pendidik dan masyarakat pun masih samar pengetahuannya mengenai kesehatan seksual.

Ibu R juga memiliki pandangan yang menarik mengenai seks dan gender. Ibu $\mathrm{R}$ berpandangan gender memiliki makna yang sama dengan seks, padahal terdapat perbedaan konsep antara seks dan gender. Menurut Meyer (2010) seks adalah tanda-tanda biologis dan fisik tertentu pada seseorang menentukan dan membangun identitas seks pada orang tersebut. Sedangkan gender (Davies \& Robinson, 2010) lebih kepada sebuah persepsi sosial dan kultural tentang sifat-sifet dan peran perempuan dan laki-laki harus diperhatikan. Gender diperoleh melalui proses pengetahuan dan proses sosialisasi dan juga melalui kebudayaan masyarakat yang mempengaruhi perkembangan seseorang.

Berbeda pendapat dengan responden pertama, $\mathrm{Ibu} \mathrm{R}$ mengemukakan bahwa melalui pendidikan seks orang tua akan mengetahui kegemaran anak sesuai dengan jenis kelaminnya. Hal tersebut dalam terlihat dalam hasil wawancara dibawah ini,

“...ya ya... kalo menurut saya pendidikan seks itu maaf yaa.. digaris bawahi masalah reproduksi, alat reproduksi, pengenalan suapaya anak mengetahui bahwa dia itu lakilaki atau perempuan. Jadi kita juga mengetahui kesukaan anak kita sesuai dengan gender anak saya laki-laki atau perempuan. Saya kan jadi tau anak laki-laki mainannya apa, alat kelaminya apa..."

“...Menurut saya pendidikan seks yang sebatas dia tau female atau male, tau batasan pegang walaupun itu ke teman perempuan dan laki-laki. Diajarkan privasi bahwa itu (alat kelamin) boleh diajarkan tapi jangan diajarkan cara reproduksinya. Sekarangkan perkembangan anak reproduksinya untuk pipis dan masa oral belum ke cara reproduksinya. Disesuaikan dengan umurnya..."

(Wawancara Responden 2/Ibu R, 17

Mei 2016)

Dalam penggalan wawancara di atas, Ibu $\mathrm{R}$ sudah memiliki bekal pendidikan seks yang baik dan benar pada anak. Ia berpendapat pendidikan seks merupakan pengenalan anak mengenai jenis kelamin laki-laki dan perempuan, cara mengajarkan batasan anak dengan orang asing dan mengajarkan anak bagaimana cara buang air kecil dengan benar sesuai dengan umur dan perkembanganya (Sciaraffa \& Randolph, 2011).

Berbeda dengan pandangan responden ketiga yaitu Bapak $\mathrm{S}$ 
mengenai pendidikan seksual. Ketika peneliti mewawancarai Bapak $\mathrm{S}$ mengenai pengertian pendidikan seksual, terlihat dari gestur tubuh bawasanya bapak $\mathrm{S}$ mengalami kebingungan. Bapak $\mathrm{S}$ berpendapat bahwa pendidikan seksual pada anak dapat dilakukan dengan mengenalkan dampak-dampak dari gagalnya pendidikan seksual secara medis maupun secara agama yang dapat terlihat pada wawancara dibawah ini:

“....Bentar-bentar bagaimana de... yaa mungkin ada yang lebih ahlinya ya tentang pendidikan seks itu mungkin sepengetahuan saya salah satunya untuk anak dibawah umur itu salah satu pengenalan alat alat reproduksi itu.. terus yaa hormon-hormon segala macem"

(Wawancara Responden 3/ Bapak S, 16

Mei 2016)

Walaupun bapak $\mathrm{S}$ terlihat kebingungan ketika peneliti bertanya mengenai pendidikan seks, bapak $\mathrm{S}$ tetap memberikan pandangan bahwa pendidikan seks memang penting untuk diberikan kepada anak.

“...Perlu.. untuk pengenalan perlu bahayanya, secara agama juga, secara medis juga. Mungkin secara bertahap kali yaa, kita kan harus melihat kapasitas anak juga. Apakah umur sekian pendidikannya bagaimana"

(Wawancara Responden 3/ Bapak S, 16

Mei 2016)

Kebingungan orang tua terhadap pendidikan seks bukan hanya dialamin Pak S. Pemahaman yang hampir sama juga diungkapkan oleh Bapak J, seperti pada cuplikan di bawah ini.

“...Pendidikan seksual... Apa

ya? (kebingungan) pendidikan seksual..."

(Wawancara Responden 4/ Bapak J, 16

Mei 2016)

“...Hmm mungkin kaya pelecehan seksual saya tau, kasus-kasus perkosaan juga. Pokoknya hal-hal yang berbau dengan kejahatan pelecehan seksual seperti itu. Kalo saya dulu SMA mah yang seperti itu teh mengarah ke hubungan orang dewasa. Mungkin seperti itu kali ya neng?..."

(Wawancara Responden 4/Bapak J, 14

Mei 2016)

Petikan wawancara di atas tersebut mengungkapkan bahwa Bapak J mengalami kecemasan seperti bapak S. Pengertian pendidikan seks menurut Bapak J mengarahkan pada hubungan orang dewasa dan cara intervensi kekerasan seksual. Kecemasan orang tua tentang seksualitas anak-anak sering berasal dari kesalahpahaman bahwa anak-anak memiliki pemikiran seperti orang dewasa. Ada perbedaan yang jelas antara seksualitas anak-anak dan seksualitas dewasa (Sciaraffa \& Randolf, 2011).

Berdasarkan seluruh hasil wawacara dengan para responden, pandangan orang tua mengenai pendidikan seks pada anak usia dini dapat diuraikan sebagai berikut:

1. Keempat subjek penelitian menyadari bahwa pendidikan 
seks bagi anak usia dini memang penting untuk diberikan.

2. Orang tua berpendapat bahwa pendidikan seks untuk anak usia dini dibatasi lebih kepada pengenalan jenis kelamin baik perempuan maupun laki-laki.

3. Masih terdapat kebingungan antara pemahaman pendidikan seks untuk anak usia dini dan pendidikan seks untuk orang dewasa (Pop dan Rusu, 2015). Orang tua masih berpandangan bahwa pendidikan seks untuk anak merupakan suatu pemikiran yang dewasa.

\section{SIMPULAN}

Berdasarkan hasil penelitian di atas dapat disimpulkan bahwa orang tua memiliki pandangan bahwa pendidikan seks untuk anak merupakan hal yang penting, namun lebih kepada pengenalan jenis kelamin sebagai perempuan atau laki-laki. Adapun rekomendasi yang dapat diberikan yaitu terkait pengenalan pendidikan seks untuk anak hendaknya orang tua menggali informasi lebih lanjut terkait dengan berbagai cara pengenalan yang sesuai dengan usia dan tahap perkembangan anak. 


\section{DAFTAR PUSTAKA}

Ching, L. (2005). An Exploratory Study Of Parents' Perceptions Of Teaching Sex Education In Hong Kong Preschools. Issues in Early Childhood, 11(3), 249262

Chrisman, K., \& Couchenour, D. (2002). Healthy Sexuality Development: A Guide for Early Childhood Educators and Families. NAEYC, PO Box 932569, Atlanta, GA 311932569.

Cohen, S. (2009). Hey, Do I Say? (A Parent To Parent Guide On HowTo Talk To Children About Sexuality). New York : Planned Parenthood

Coleman, H \& Charles, G. (2009). Sexual Development and Behavior in Children (Information for Parents and Caregivers). [Online] diakses di www.NCTSN.org

Counterman, L \& Kirkwood, D. (2013). Understanding Healthy Sexuality Development in Young Children. Pediatric Clinics of North America, 50(4), 765-780.

Creswell, J, W. (2013). Research design: Pendekatan Kualitatif, Kuantitatif dan Mixed. Yogyakarta: Pustaka Pelajar.

Davies, C., \& Robinson, K. (2010). Hatching babies and stork deliveries: Risk and regulation in the construction of children's sexual knowledge. Contemporary Issues in Early Childhood, 11(3), 249-262.

Honig, A. (2000). Psychosexual Development in Infants and Young Children: Implications for Caregivers. Toronto : Young Children 55 (5): 70-77.
Karahalis, Yiorgos. 2014 Empat Bulan, 200 Anak Jadi Korban Kekerasan Seks. Jakarta : diakses pada 30 Juli 2016 di www.tempo.com

KPAI. (2016). Darurat Kekerasan Pada Anak. Jakarta. [Online] diakses dari www.kpai.com pada tanggal 23 Februari 2016

Kurnia, N \& Tjandra, E. (2012). Bunda, Seks itu Apa Sih? (Cara Bijak menjelaskan Seks pada Anak). Jakarta : Gramedia

Kusmiati. (2015). 1.600-an Kasus Kekerasan Anak di 2013, Meningkat 60 Persen. Jakarta: diunduh pada 11 Januari 2016 di www.liputan6.com

Luluk, H. 2015. Kekerasan Seksual pada Anak (Studi Kasus di Kabupaten Jember tahun 2014). Jakarta : Jurnal Pendidikan Anak Usia Dini Universitas Pendidikan Jakarta Vol. 9 Edisi 2, November 2015

Mariani, A \& Bachtiar, I. (2010). Keterpaparan Materi Pornografi dan Perilaku Seksual Siswa Sekolah Menengah Pertama Negeri. Makara, Sosial Humaniora, VoL. 14, No. 2, 8390

Maslihah, S. (2006). "Kekerasan Terhadap Anak: Model Transisional dan Dampak Jangka Panjang. Edukid : Jurnal Pendidikan Anak Usia Dini. I (1).25-33

Meyer, E. J. (2010). Gender and sexual diversity in schools (Vol. 10). Springer Science \& Business Media.

Nainggolan, L. H. (2008). BentukBentuk Kekerasan Seksual Terhadap Anak Di Bawah Umur. Jurnal Equality, Vol. 8(8), 411-417. 1

Pittkof, E. (2008). Protecting your Child By Talking About 
Growth,Development and Your Child's Sexuality. Newton Public School diunduh pada 10 November $2015 \quad$ di www.familiesaretalking.org

Rahmawati, N. (2012). Gambaran Perilaku Seksual Pada Anak Usia Sekolah Kelas 6 Di Tinjau Dari Media Cetak Dan Media Elektronik. Banda Aceh : Jurnal Keperwatan Masyarakat, 8(8), 411-417.

Sciaraffa, M \& Randholph, T. (2011). "You Want Me to Talk to Children About What? Responding to the Subject of Sexuality Development in Young Children." Young Children. Journal NAEYC. (19), 37-46.

SEF. (2011). Key findings Young people's survey on sex and relationships education. [Online] diakses di www.sexeducationforum.org.u k pada tanggal 21 Februari 2016

Sexuality Information and Education Council of the United States (SIECUS). (2004). Guidelines for Comprehensive Sexuality Education Kindergarten through 12th Grade. National Guidelines Task Force. 3rd Edition. Washington, D.C.: SIECUS.

Sexuality Information and Education Council of the United States (SIECUS). (2011). Guidelines for Comprehensive Sexuality Education Kindergarten through 12th Grade. National Guidelines Task Force. 3rd Edition. Washington, D.C.: SIECUS.

Sucahyo. N. 2016. Indonesia Darurat Kekerasan terhadap Perempuan. Jakarta : diakses pada 30 Juli 2016 di www. voaindonesia.com Sugiasih, I. (2010). Need Assessment Mengenai

Pemberian
Pendidikan Seksual Yang Dilakukan Ibu Untuk Anak Usia 3-5 Tahun. Fakultas Psikologi Universitas Islam Sultan Agung : Jurnal Proyeksi, Vol. 6 (1), 7181

Wardle, F. (2007). The expected and the dysfunctional: Dealing with child-to-child sexual behavior. Contemporary Issues in Early Childhood, 14(1), 81-87. 